\title{
$\mathrm{Ge}_{2} \mathrm{Sb}_{2} \mathrm{Te}_{5}$ nanowire arrays와 PEDOT: $\mathrm{PSS}$ 를 이용한 유·무기 열전 복합소재 합성 및 특성평가

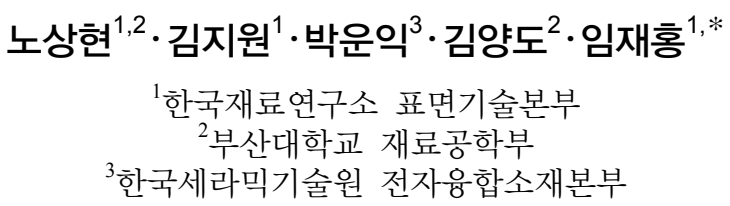

\section{Fabrication and Characterization of $\mathrm{Ge}_{2} \mathrm{Sb}_{2} \mathrm{Te}_{5}$ Nanowire Arrays and PEDOT: PSS Hybrid Thermoelectric Composites}

\author{
Sang-Hyun Roh ${ }^{1,2}$, Jiwon Kim ${ }^{1}$, Woon-Ik Park ${ }^{3}$, Yang-Do Kim ${ }^{2}$, and Jae-Hong Lim ${ }^{1, *}$ \\ ${ }^{1}$ Surface Technology Division, Korea Institute of Materials Science, Changwon 51508, Republic of Korea \\ ${ }^{2}$ Department of Materials Science and Engineering, Pusan National University, Busan 46241, Republic of Korea \\ ${ }^{3}$ Electronic Materials \& Component R\&D Center, Korea Institute of Ceramic Engineering \& Technology (KICET), Jinju \\ 52851, Republic of Korea
}

\begin{abstract}
Hybrid organic/inorganic composites have recently been investigated in the thermoelectric field in an effort to interdependently manipulate the charge carriers, which are interconnected with electrical and thermal transport. The decoupling of a charge carrier's roles in the hybrid structures can result in enhanced thermoelectric performance, by only exploiting the high seebeck coefficient of the inorganic part and the high electrical conductivity of the organic part. In this work, we demonstrated the enhanced thermoelectric performance of poly(3,4-ethylenedioxythiophene):poly(styrenesulfonate) (PEDOT:PSS) by employing the nanoimprinted $\mathrm{Ge}_{2} \mathrm{Sb}_{2} \mathrm{Te}_{5}$ nanowire arrays to form a vast network of PEDOT:PSS/ $\mathrm{Ge}_{2} \mathrm{Sb}_{2} \mathrm{Te}_{5}$ nanowire composites. These structures showed an approximately ten times higher Seebeck coefficient than the PEDOT:PSS itself without damaging electrical conductivity. In addition, ethylene glycol (EG) was used to selectively de-dope PSS, to enhance the electrical conductivity of the composites. Different EG concentrations were needed to optimize the de-doping effect, and the best thermoelectric power factor (P.F.) of $\sim 1.6 \times 10^{3} \mu \mathrm{W} / \mathrm{mK}^{2}$ was achieved with an EG level of $6 \mathrm{vol} \%$ in our configuration. This result is 5 times and 22 times higher than that of GST thin film $\left(320 \mu \mathrm{W} / \mathrm{mK}^{2}\right)$ and PEDOT:PSS/Te nanorods composites $(70.9 \mu$ $\mathrm{W} / \mathrm{mK}^{2}$ ). Electrical and thermoelectric measurements were conducted in both parallel and perpendicular directions to observe the dependence of the transport property on the charge carrier pathway under the influence of the interface, to achieve a higher thermoelectric P.F.. The parallel direction was 1.6 times higher than the perpendicular direction.
\end{abstract}

(Received October 4, 2016; Accepted December 1, 2016)

Keywords: thermoelectric, composite, PEDOT:PSS, $\mathrm{Ge}_{2} \mathrm{Sb}_{2} \mathrm{Te}_{5}$.

\section{1. 서 론}

현대의 산업발달로 고갈되는 에너지자원으로 인해 값싸고 재활용이 가능한 대체 에너지 자원의 연구 개발이 활발하게 진행되고 있다. 열전 소자는 폐열, 빛, 진동, 운동 에너지 등을 전기에너지로 변환하여 연료의 효율을 향상 시키는 에너지 하베스팅 (Energy harvesting) 기술이 활발히 연구되고 있다

*Corresponding Author: Jae-Hong Lim

[Tel: +82-55-280-3523, E-mail: lim@kims.re.kr]

Copyright (c) The Korean Institute of Metals and Materials
[1,2]. 특히 열전 재료는 재료 양단의 온도차이로 Seebeck 효 과와 Peltier 효과를 이용하여 열전 냉각, 발전, 광통신, 의료 시스템, 태양에너지, 전기장치 등에 응용이 가능하다 [3]. 이 러한 열전 소재는 무차원 값인 열전성능지수 (Figure of merit, ZT)로 나타낼 수 있으며, 이는 식 $\mathrm{ZT}=\mathrm{S}^{2} \sigma \mathrm{T} / \kappa$ 로 정의 된다 [4]. 열전성능지수 식에서 제벡계수 (Seebeck coefficient)는 $\mathrm{S}$, 전기전도도 (electrical conductivity)는 $\sigma$, 절 대온도는 T, 열전도도 (Thermal conductivity)는 $\kappa$ 로 나타낸 다. 열전성능지수를 증가하기 위해서는 전기전도도와 제벡 
계수의 증가 그리고 열전도도의 감소에 의해 이루어진다. 박 막의 경우 열전도도 측정이 어렵기 때문에 파워 팩터 (power factor)로 나타낸다. 이는 열전성능지수에서 분모에 위치한 $\mathrm{S}^{2} \sigma$, 즉 제벡계수의 제곱과 전기전도도의 곱으로 이루어진 식이다 [5].

$\mathrm{Ge}_{2} \mathrm{Sb}_{2} \mathrm{Te}_{5}(\mathrm{GST})$ 는 다양한 칼코제나이드 물질 중의 한 물 질로써, 열처리를 통한 상변화가 용이하여 상변화메모리, 디 지털 다목적 디스크, 열전 발전기 등에 응용 발전 될 수 있다. 제벡계수는 상의 변화와 공정조건에 크게 의존한다. GST는 $\mathrm{Sb}_{2} \mathrm{Te}_{3}$ 계의 열전재료인 P형 화합물이며, GST 필름의 두께와 비정질 또는 결정성과 같은 phase change에 관한 논문들이 많이 보고되었다 [6]. GST에는 암염구조 (rocksalt structure) 와 육방밀집구조 (hexagonal close packing)의 2가지의 결정 구조가 나타나는데, 열처리를 통해 그 결정구조를 갖게 된다. 미국의 스텐퍼드 대학의 Goodson 교수 연구 그룹에서 GST 는 상온의 경우 다른 칼코제나이드 물질 $\left(\mathrm{Sb}_{2} \mathrm{Te}_{3}, \mathrm{Bi}_{2} \mathrm{Te}_{3}\right)$ 보다 큰 제벡계수를 갖고 있음이 확인되었다. 비정질 GST의 경우 상온에서 $500 \mu \mathrm{V} / \mathrm{K}$ 의 제벡계수를 가지고 있으나 $10^{-4} \mathrm{~S} / \mathrm{cm}$ 에 해당하는 낮은 전기전도도가 측정된다. 그러나 열처리를 통해 결정성을 증가시킬 수 있으며, 열처리 온도 변화 및 결 정성 향상에 따라서 전기전도도는 증가, 제벡계수는 감소하 게 된다 [7].

무기물은 제작에 어려움이 많고, 독성이 강하여 환경오염 에 대한 문제가 있다. 또 제작 비용이 적지 않다는 단점이 있 다. 이러한 무기물의 한계와 1970년대에 도핑을 통해 높은 전기전도도를 가지는 polyacetylene의 발견으로 전도성 고분 자가 주목을 받기 시작하였다 [8]. 다양한 전도성 고분자 중 에서도 Poly(3,4-ethylenedioxythiophene):poly(styrenesulfonate) (PEDOT:PSS)는 값싸고 제조가 쉬우며, 높은 전기전도도에 비해 열전도도가 낮아 열전 물질로 각광받고 있다. 하지만 무 기물에 비하여 제벡계수가 상당히 낮으며 도핑을 할 경우 전 도도가 크게 증가하면서 제벡계수가 감소하기 때문에 쉽게 상용화되기 어려운 단점이 존재한다 $[9,10]$

제벡계수, 전기전도도, 열전도도는 모두 상호관계를 갖게 되는데, 즉 제벡계수가 증가하면 전기전도도는 감소하고 열 전도도 또한 감소하는 경향을 가진다. 전기전도도가 증가하 면 열전도도 또한 증가하며 제벡계수는 감소하게 된다. 이러 한 상호관계를 decoupling 하는 방안을 계속해서 연구 중이 다 [11]. 그 중 높은 제벡계수를 가지는 무기물과 높은 전기전 도도를 가지는 폴리머를 복합체를 형성하여 각각의 장점을 이용하는 것이 주된 관심사로 떠오르고 있다. 미국 캘리포니
아 대학의 Segalman 교수 연구 그룹은 $\mathrm{Te}$ nanorods와 PEDOT:PSS를 이용하여 복합체를 형성하여 파워팩터 70.9 $\mu \mathrm{W} / \mathrm{mK}^{2}$ 를 얻었고 Te nanorods의 파워팩터 $2.7 \mu \mathrm{W} / \mathrm{mK}^{2}$ 및 PEDOT:PSS의 파워팩터 $0.05 \mu \mathrm{W} / \mathrm{mK}^{2}$ 보다 복합체의 열전 특성이 뛰어남을 보여주었다 [12]. 델라웨어 대학의 Opila 교 수 연구 그룹은 PEDOT:PSS 박막에 $\mathrm{Bi}_{2} \mathrm{Te}_{3}$ particles를 채워 제벡 및 파워팩터를 $131 \mu \mathrm{W} / \mathrm{mK}^{2}$ 으로 향상 시켰다 [13] Seglman 교수 연구 그룹의 다른 결과로 $\mathrm{Te}$ nanowires와 PEDOT:PSS로 유/무기 복합체를 형성한 후, Te nanowires의 함량을 조절하여 열전 특성을 분석 하였으며 Te nanowires의 방향성이 열전 특성에 변화를 주어 열전특성을 변화시키는 것을 보여주었다 [14]. 중앙대의 김주헌 교수 연구 그룹은 최 근에 각광받는 물질인 $\mathrm{SnSe}$ 를 나노구조체인 nanosheets로 제작하여 PEDOT:PSS와 복합체를 형성하였으며 $386 \mu$ $\mathrm{W} / \mathrm{mK}^{2}$ 에 해당하는 높은 파워팩터를 얻었다 [15]. 이외에도 중국 상하이 세라믹스연구소의 Chen 박사 연구 그룹에서는 유기물인 Single-walled carbon nano tube (SWCNT)와 Polyaniline(PANI)으로 복합체를 형성하여 폴리머 사슬의 정 렬로 인한 전기전도도 향상 및 열전 특성을 향상 시켰으며 베 이징의 칭화대학의 $\mathrm{Liu}$ 교수 연구그룹에서는 carbon nanotube와 PANI 복합체를 형성하여 열전 특성을 확인하는 등, 다양한 복합체가 연구되고 있다 $[16,17]$.

하지만 이러한 연구는 고분자 매트릭스에 무기물의 분산 제어가되지 않아 charge path way를 제어하기 어렵기 때문에 전기전도도와 파워팩터가 낮다는 문제점이 존재한다. 이러 한 문제점을 해결하고자 본 연구에서는 상온에서 높은 제벡 계수를 가지는 동시에 낮은 전기전도도를 갖는 무기열전소 재 GST를 나노와이어 array로 형성하였고, $\mathrm{EG}$ 를 도핑하였을 때 높은 전기전도도를 가지며 전기전도도를 제어할 수 있는 유기물 PEDOT:PSS를 복합화하여 열전 특성에 대해서 고찰 하였다. GST는 나노임프린팅으로 제작한 1차원 nanowire arrays를 사용하여 PEDOT:PSS와의 접촉면적의 증가로 계면 간 상호작용을 원활하도록 하였다. 먼저 PEDOT:PSS에 EG doping을 하여 X선 회절 분석과 Raman spectroscopy, Seebeck측정, 4 Point prove 측정장치를 이용하여 전기전도 도, 제벡계수를 측정 하였다. 또 복합체의 구조적 특성을 알 아보기 위하여 $\mathrm{X}$ 선 회절 분석을, 전기적, 열전 특성 분석 및 방향성에 따른 열전 특성 변화를 확인하기 위하여 가로, 세로 방향을 Seebeck 측정, 4 Point prove 측정장치를 이용하여 복 합체의 1차원 GST nanowire arrays 방향성에 대한 열전 특성 변화를 알아보고자 하였다 [18]. GST nanowire arrays/ 
PEDOT:PSS 복합체는 기존의 열전 나노와이어와 유기물의 복합 열전소재의 특성보다 높은 파워팩터인 $1.6 \times 10^{3} \mu$ $\mathrm{W} / \mathrm{mK}^{2}$ 을 얻었다. 이는 GST 나노와이어의 방향성을 제어하 여 결과를 얻은 것으로 사료된다.

\section{2. 실험방법}

\subsection{GST nanowire array 형성}

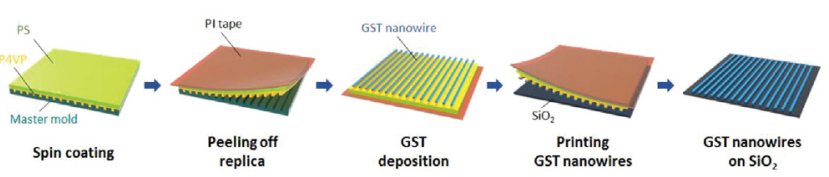

Fig. 1. Scheme of developing GST nanowire arrays on $\mathrm{SiO}_{2}$ substrate using anano pattern printing method.

GST nanowire array는 나노 패턴전사 프린팅 기법을 이용 하여 $\mathrm{SiO}_{2}$ 기판에 GST nanowire arrays를 형성 하였다 (그림 1). 우선, 폭 $1 \mu \mathrm{m}$ 와 깊이 $40 \mathrm{~nm}$ 를 가지는 Si guiding template 에 poly (styrene- $b$-dimethylsiloxane) (PS- $b$-PDMS) 블록공중 합체를 정렬시켜, $18 \mathrm{~nm}$ 선폭을 갖는 라인패턴의 master mold를 제작하였다. 복제 패턴을 만들기 전에 master mold에 hydroxyl-terminated polydimethylsiloxane (OH-PDMS)를 이 용하여 표면처리를 하였다. 이 master mold에 polystyrene (PS)와 poly(4-vinyl pyridine) (P4VP)를 스핀코팅 후 PI tape 로 떼어내어 역상의 라인복제 패턴을 만든다. 만들어진 복제 패턴에 스퍼터를 이용하여 $\mathrm{GST}$ 를 증착한 후 $\mathrm{SiO}_{2}$ 기판에 프 린팅하였다. 마지막으로, GST위에 존재하는 복제패턴 소재 인 P4VP/PS layer를 톨루엔으로 제거하여 약 $18 \mathrm{~nm}$ 선폭을 갖는 pure GST nanowire array를 얻을 수 있었다.

\subsection{PEDOT:PSS 용액 제조 및 박막 형성}

PEDOT:PSS의 도핑에 따른 열전 특성을 확인 하기 위하여 PEDOT:PSS용액을 제조하였다. 부피 비에 따라 EG를 2, 4, $6,8,10 \%$ 를 각 바이알 병에 담긴 PEDOT:PSS용액에 첨가하 였다. PEDOT:PSS용액은 Clevios ${ }^{\mathrm{TM}} \mathrm{PH} 1000$ 용액을 사용하 였고, EG는 Ethylene glycol 99.5\% extra pure (Samchun)를 사용하였다. $2 \times 2 \mathrm{~cm}$ 유리 기판을 오존처리 하여 혼합용액 의 퍼짐성을 강화하고, 표면을 클리닝 하였다. 유리기판에 혼 합용액을 스핀코팅을 하고 $120{ }^{\circ} \mathrm{C}$ 에서 3 분간 열처리를 하여 PEDOT:PSS 박막을 제작하였다.

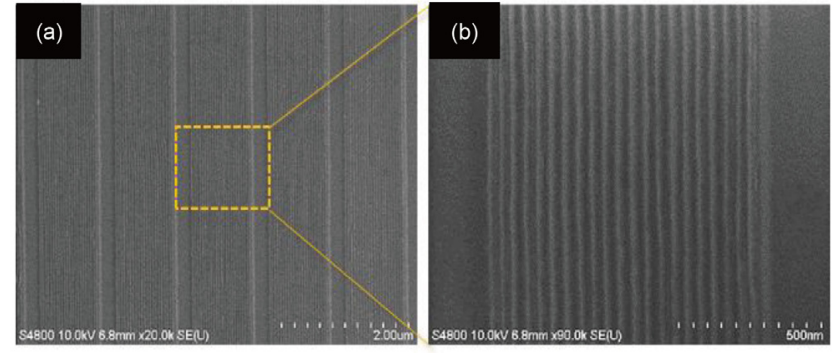

Fig. 2. SEM image of nanoimprinted $\mathrm{Ge}_{2} \mathrm{Sb}_{2} \mathrm{Te}_{5}$ nanowire arrays (top view) (a). zoom-in image of $\mathrm{Ge}_{2} \mathrm{Sb}_{2} \mathrm{Te}_{5}$ nanowire arrays (b).

\subsection{GST 복합체 형성}

GST nanowire array가 형성된 $\mathrm{SiO}_{2}$ 기판을 오존처리 하여 $\mathrm{PEDOT}: \mathrm{PSS} / \mathrm{EG}$ 혼합용액의 퍼짐성을 향상 시켰다. 오존 처 리된 GST nanowire array에 혼합용액을 스핀코팅 하고 120 ${ }^{\circ} \mathrm{C}$ 에서 3 분간 열처리하여 복합체를 제작 하였다.

\section{4 제작된 PEDOT:PSS 박막 및 GST 복합체의 분석}

나노 임프린팅에 의해 제작된 GST nanowire array의 표면 형상을 알아보기 위하여 주사전자현미경 Scanning Electron Microscopy (SEM)을 이용하여 관찰하였다. 또한 이 형성된 복합체의 $\mathrm{X}$ 선 회절 패턴을 알아보기 위하여 5 40 (20 degree) 에서 측정하였다. 복합체 및 단일 PEDOT:PSS 박막 의 구조적 특성을 보기 위하여 전자동 X-선 회절분석장치 (XRD : X-ray diffraction, MULTI PURPOSE HIGH RESOLUTION X-RAY DIFFRACTOMETER, X'PERT PRO, PANALYTICAL, Netherlands)을 이용하였으며, EG 의 도핑에 따른 PEDOT:PSS의 구조변화는 고분해능 라만 분 광기 (High Resolution Raman Spectrometer, LABRAM HR, HORIBA JOBIN YVON SAS, KOREA)를 측정하였다. 일함 수 (work function)측정을 위하여 UV Photoelectron Spectroscopy (UPS : UPS, AXIS-NOVA, Kratos inc.)를 이용 하였다.전기적 물성과 제벡계수를 측정하기 위하여 자체 제 작한 제백계수 측정장치와 Hall measure, 4 Point probe를 사 용하여 제벡계수, 전기전도도를 평가 하였다. 제벡계수는 3 ${ }^{\circ} \mathrm{C}$ 씩 증분하여 제벡계수 측정장비에서 계산된다.

\section{3. 실험 결과 및 고찰}

그림 2의 (a)는 nanowire array의 top view 사진이며 (b)는 단일개체 nanowire array를 확대하여 관찰 하였다. 각각의 GST nanowire 의 두께는 약 $22 \mathrm{~nm}$ 를 가지며, 하나의 


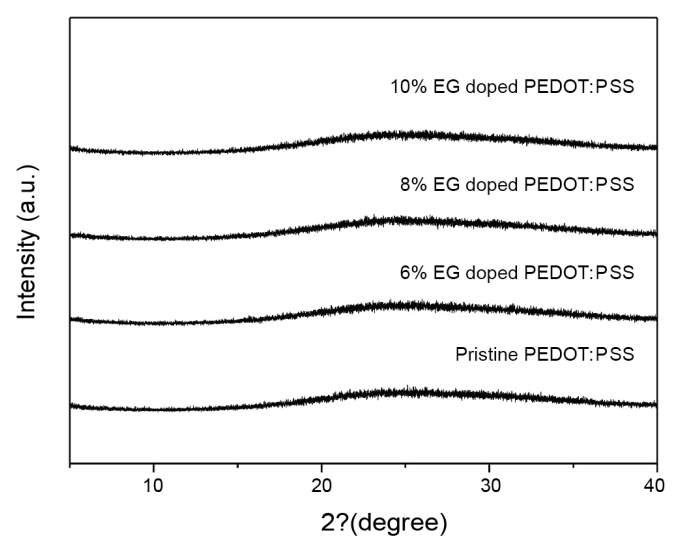

Fig. 3. XRD patterns of pristine and EG doped PEDOT:PSS films.

nanowire array는 22개의 nanowires로 구성되어 있다. 각각의 nanowire array 간격은 약 $200 \mathrm{~nm}$ 이며 한 방향으로 정렬되어 있음을 확인 할 수 있었다.

$\mathrm{EG}$ 가 도핑된 PEDOT:PSS 박막의 결정구조를 확인하기 위하여 $\mathrm{X}$ 선 회절 분석을 측정하였다 (그림 3). 회절패턴 분석 결과 EG 도핑은 PEDOT:PSS 박막의 결정성에 영향을 끼치 지 않았다. 그 이유는, PEDOT:PSS의 결정성은 PSS함량에 따라 변화하고 그 결과, carrier concentration과 전도도에 영 향을 미치게 된다 $[19,20]$. 본 실험에서는 일정한 양의 $\mathrm{PSS}$ 를 포함하는 PEDOT:PSS용액을 사용하였기 때문에 EG의 도핑 에 따라 PEDOT:PSS의 결정구조의 변화 없이 PEDOT:PSS 의 전기적 특성만을 선택적으로 제어할 수 있었다.

그림 4는 EG 도핑 농도에 따른 PEDOT:PSS film의 내부 사슬 변화를 라만 분광기를 통하여 분석한 결과를 보여준다. $3(\mathrm{a})$ 는 $500 \mathrm{~cm}^{-1}$ 에서 $2000 \mathrm{~cm}^{-1}$ 의 범위에서 Raman을 측정하 였다. EG의 도핑농도에 따라서 사슬의 intensity가 크게 관측 됨을 알 수 있다. $1509 \mathrm{~cm}^{-1}$ 와 $1503 \mathrm{~cm}^{-1}$ 의 피크는 $\mathrm{C}=\mathrm{C}$ 의 비 대칭 진동이다. $1400 \mathrm{~cm}^{-1}$ 에서 $1470 \mathrm{~cm}^{-1}$ 사이의 피크 또한 $\mathrm{C}=\mathrm{C}$ 비대칭 진동을 의미한다. $1365 \mathrm{~cm}^{-1}$ 의 흡수파장은 $\mathrm{C}-\mathrm{C}$ 스트레칭, $1269 \mathrm{~cm}^{-1}$ 와 $1266 \mathrm{~cm}^{-1}$ 의 피크는 링 내의 $\mathrm{C}-\mathrm{C}$ 비 대칭 진동을 의미한다. $1105 \mathrm{~cm}^{-1}$ 와 $1102 \mathrm{~cm}^{-1}$ 는 C-O-C, 그 리고 $695 \mathrm{~cm}^{-1}$ 와 $701 \mathrm{~cm}^{-1}$ 는 C-S-C의 결합을 의미한다. 또 $576 \mathrm{~cm}^{-1}$ 와 $987 \mathrm{~cm}^{-1}$ 은 옥시 에틸렌 링을 의미한다. 3(b)는 $1400 \mathrm{~cm}^{-1}$ 에서 $1470 \mathrm{~cm}^{-1}$ 피크를 확대하여 나타낸 그림이다. Pristine PEDOT:PSS와 비교하여 EG 도핑량이 증가함에 따 라 피크가 왼쪽으로 shift하는 것을 볼 수 있다. 이러한 shift는 공명구조인 PEDOT 사슬이 코일처럼 꼬여있던 benzoid 구조 에서 선형 구조인 quinoid 구조로 변형 되었음을 나타낸다.
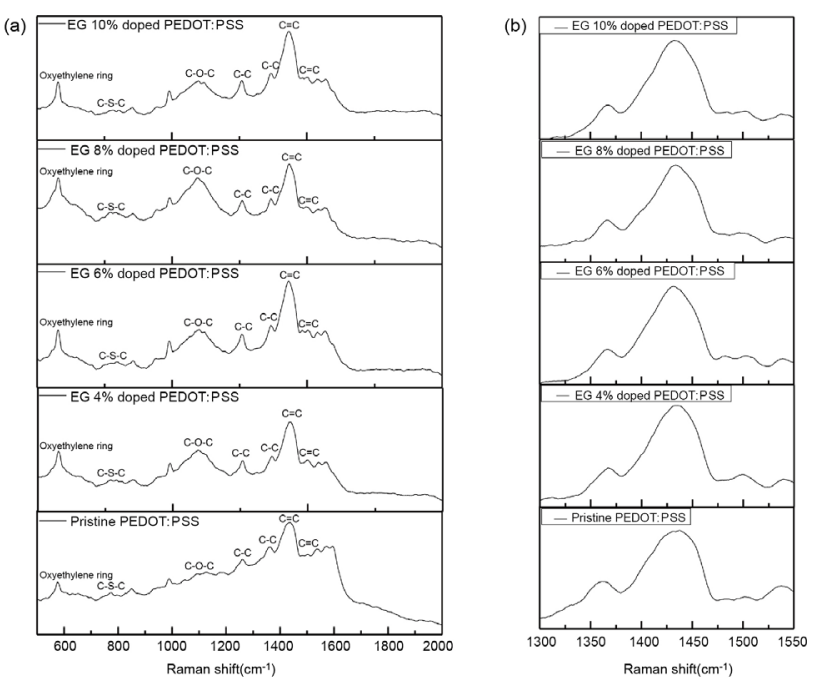

Fig. 4. Raman spectra of PEDOT:PSS films from $500 \mathrm{~cm}^{-1}$ to $2000 \mathrm{~cm}^{-1}$ (a). Raman spectra of PEDOT: PSS films from 1300 $\mathrm{cm}^{-1}$ to $1550 \mathrm{~cm}^{-1}$ (b).

Pristine PEDOT:PSS는 절연체인 PSS상이 PEDOT chain을 감싸고 있기 때문에 전자전이가 일어나기 쉽지 않다. 하지만 $\mathrm{EG}$ 의 도핑에 의해 PEDOT:PSS상에 존재하는 과량의 PSS상 을 분산시키고 각 결정상의 PEDOT chain이 직선형으로 바 뀌어, 보다 쉽게 전자의 전이가 일어나 전기전도도가 향상됨 을 예측할 수 있다 [21].

그림 5는 EG 도핑 농도에 따른 PEDOT:PSS 박막의 열전 특성을 나타내었다. 그림 5(a)에서 $\mathrm{EG}$ 도핑 농도에 따라 제 벡계수의 변화를 나타내었는데, $\mathrm{EG}$ 도핑의 $\mathrm{vol} \%$ 가 커질 수 록 PEDOT:PSS film의 제벡계수는 감소하는 경향을 보였다. 제벡계수는 $0 \%$ 에서 $16.1 \mu \mathrm{V} / \mathrm{K}$ 으로 최대 값을 보였으며, $10 \%$ 에서 $12.5 \mu \mathrm{V} / \mathrm{K}$ 로 가장 낮은 값을 보였다.

그림 5(b)에서는 EG 도핑 농도에 따른 전기전도도를 보여 주고 있다. 전기전도도는 $\mathrm{EG}$ 를 도핑하지 않았을 때는 1.1 $\mathrm{S} / \mathrm{cm}$ 로, $\mathrm{EG}$ 의 도핑농도가 증가함에 따라 서서히 증가하여 $6 \%$ 에서 $648 \mathrm{~S} / \mathrm{cm}$, 그리고 그 값은 $10 \%$ 까지 유사하게 유지되 었다. 이는 그림 4의 결과와 상응하는데 피크의 shift가 $6 \%$ 부 터 $10 \%$ 까지 유사함에서 기인한다고 볼 수 있다. 또 그림 3 의 피크 shift가 chain의 구조 변화로 전기전도도 증가를 의미하 는 것이며 최대 $742.4 \mathrm{~S} / \mathrm{cm}$ 까지 증가함을 확인 할 수 있었다.

이와 같이 5(a)와 5(b) 그림은 trade-off관계를 가진다. 즉 제벡계수가 증가하면 전기전도도는 감소하는 경향을 보이며 제벡계수가 감소하면 전기전도도는 증가하는 경향을 보인 다. 이러한 식에서 열전 특성을 나타내는 제벡계수는 Mott-relation에 의해 다음과 같이 식 1로 나타낼 수 있다 

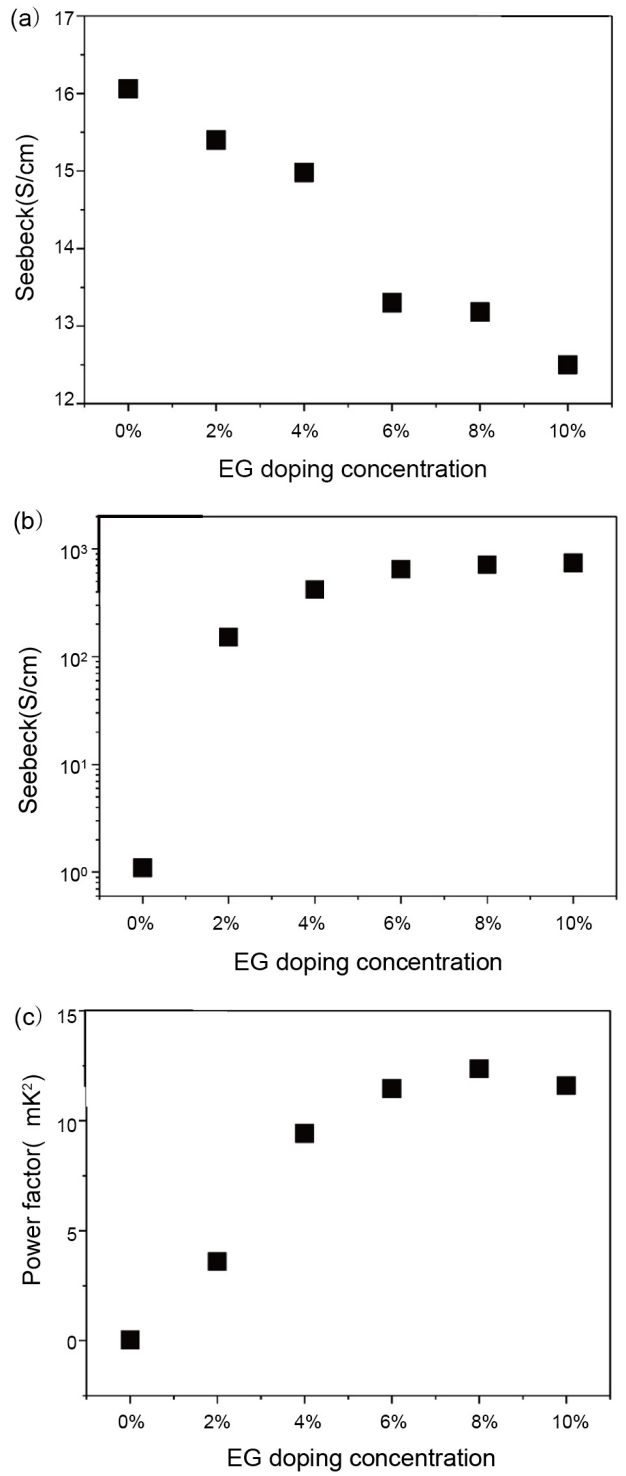

Fig. 5. Change of Seebeck coefficient (S) (a), electrical conductivity $(\sigma)(b)$, and power factor (P.F) (c) of PEDOT:PSS as a function of EG doping concentration.

$[22,23]$

$S=\frac{8 \pi^{2} \kappa_{B}^{2}}{3 e h^{2}} m^{*} T\left(\frac{\pi}{3 n}\right)^{\frac{2}{3}}$

또 전기전도도는 다음과 같은 식2로 나타낼 수 있다.

$\sigma=n \mu e$

각각의 매개 변수 중 $\mathrm{kB}$ 는 볼츠만 상수를 $\mathrm{h}$ 는 플랑크 상

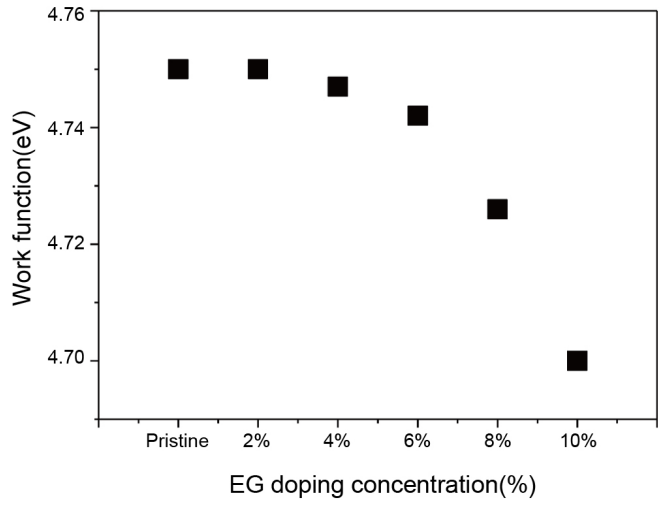

Fig. 6. work function change of PEDOT:PSS EG doping concentration.

수, $\mathrm{m}$ *는 유효질량, $\mathrm{n}$ 와 는 전자의 농도와 이동도를 각각 나 타낸다. 제벡계수 식(식 1)의 분자에, 전기전도도 식(식 2)에 존재하는 전자농도에 의해서 반비례관계가 성립 되는 것을 볼 수 있다. 이에 따라 $\mathrm{EG}$ 도핑 농도에 따른 파워팩터 $\mathrm{ngw}) \mathrm{nted} \quad 99.5 \% \mathrm{E}$ 를 계산하여 그림 5(c)에 나타내었다. 도 핑에 따라 파워 팩터가 증가하는 모습을 보이지만 $\mathrm{EG}$ 가 $8 \%$ 의 농도에서 전기전도도의 증가가 $\mathrm{EG} 6 \%$ 보다 증가하였고, 제벡계수의 감소는 거의 없기 때문에 파워팩터가 가장 높게 나타나게 되었다. 또 $\mathrm{EG} 10 \%$ 의 경우 전기전도도는 다른 농 도로 혼합된 PEDOT:PSS에 비하여 가장 높은 값이 측정되었 으나 제벡계수의 감소량이 커서 파워팩터가 $8 \%$ 보다 작게 계 산되었다. 최대 파워팩터는 $\mathrm{EG}$ 가 $8 \%$ 도핑 된 PEDOT:PSS 박막의 경우로 그 값은 약 $12.37 \mu \mathrm{W} / \mathrm{mK}^{2}$ 으로 나타났다.

앞서 측정결과를 통해 $\mathrm{EG}$ 의 양이 증가하면 제벡계수 값이 감소하고 반면 전기전도도가 증가하는 경향을 보임을 확인 하였고, 이와 같은 결과를 바탕으로 $\mathrm{EG}$ 도핑에 따른 PEDOT:PSS의 일함수 (work function) 변화를 알아보기 위 하여, UPS를 측정하였다. 이를 바탕으로 일함수를 계산 하였 다. 그림 6에 나타내어진 것처럼 $\mathrm{EG}$ 도핑 결과 PEDOT:PSS 의 일함수는 감소함을 확인 할 수 있었다. 이는 EG 도핑에 따 라 증가한 PEDOT:PSS의 전기전도도는 일함수 감소의 영향 을 받았음을 알 수 있었다.

또한, 측정된 PEDOT:PSS의 일함수 값은 알려진 GST 일 함수 값 $(4.2 \mathrm{eV})$ 과 비교하여 약 $0.5 \sim 0.56 \mathrm{eV}$ 의 차이를 가짐 을 알 수 있었다 [24]. 이러한 일함수 값의 차이는, 복합체에 서 GST와 PEDOT계면에서 밴드 접힘이 일어날 확률이 크 고, 더 높은 에너지를 가진 캐리어가 PEDOT:PSS와 GST의 계면을 이동하게 되어, 단일상 물질과 비교하여 유.무기 복합 


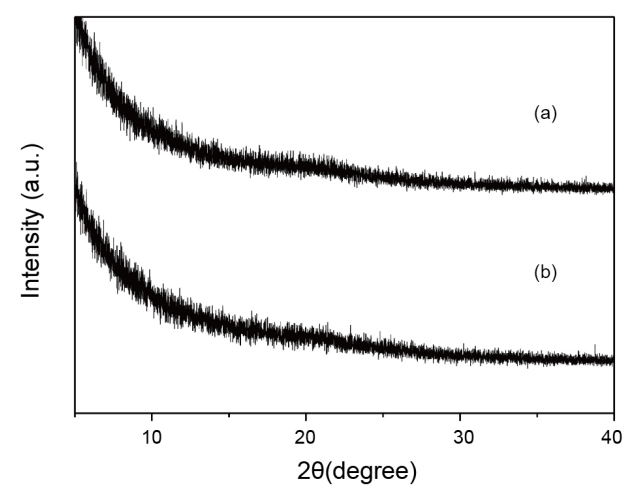

Fig. 7. XRD analysis of GST nanowire array (a) and $8 \%$ EG doped PEDOT:PSS/GST nanowire array (b). GST nanowire array is on $\mathrm{SiO}_{2}$ substrate and $8 \%$ EG doped PEDOT:PSS was spin-coated on the substrate.

체의 열전 특성이 향상됨을 기대할 수 있다 $[13,14,25,26]$

그림 7은 GST nanowire array와 8\% $\quad$ EG doped PEDOT:PSS/GST nanowire array 복합체의 구조적 특성을 알아보기 위하여 X선 회절 분석을 한 결과이다. $0 \sim 4020$ 에서 Step size $0.005^{\circ}$ scan speed $0.003333^{\circ} / \mathrm{s}$ 의 조건으로 분석을 진행 하였다. 회절패턴을 측정 한 결과, nanoimprinted GST nanowire arrays는 피크가 측정되지 않는 amorphous한 상태 임을 확인 할 수 있었다. 복합체의 XRD 측정 결과, GST nanowire array와 회절 패턴이 유사하였고 이는 복합체는 단 일상과 비교하여 상분리 또는 결정구조의 변화가 없음을 알 수 있었다.

이와 같은 데이터를 바탕으로 composite을 형성하여 열전 특성을 측정하여 보았다. 형성하며 기대한 효과는 PEDOT: PSS가 carrier들이 이동할 수 있는 matrix가 되고, GST nanowire의 존재로 제벡계수가 증가 함을 기대할 수 있고 또한 PEDOT:PSS와 GST nanowire계면에서의 carrier scattering에 의한 제벡계수의 향상 또한 기대 할 수 있다. 또한 array 방향 에 따라 전기전도도가 변화할 것임을 예상하여, 향에 따라 제 벡계수 및 전기전도도를 측정해 보았다. 이때 nanowire arrays 의 방향성에 따라 가로 및 세로 방향으로 측정하여 보 았다.

그림 8(a)는 GST/PEDOT:PSS composite의 전기전도도와 제벡계수를 나타낸 그래프이다. 그림에서 삼각형 심볼이 EG $6 \%$ 를 첨가한 PEDOT:PSS와 GST composite 이며, 사각형 심 볼이 $\mathrm{EG} 8 \%$ 를 첨가한 composite, 원형 심볼이 $\mathrm{EG}$ 를 $10 \%$ 첨 가한 GST nanowire/PEDOT:PSS composite이다. 또한 가로 로 측정한 값은 붉은색으로, 세로로 측정한 값은 검은색으로 나타내었다. 측정 결과, $\mathrm{EG}$ 도핑량의 증가에 따라 composite

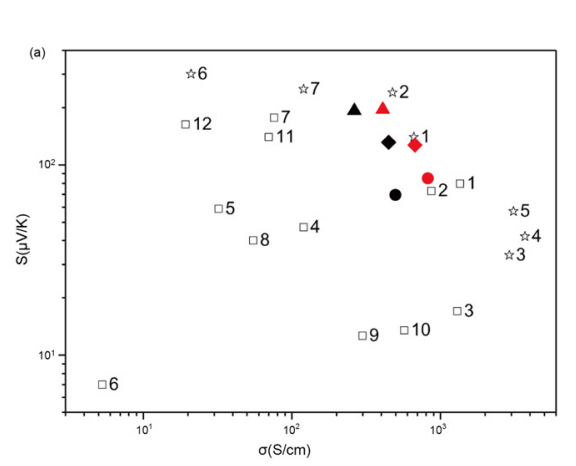

4. $1 . \mathrm{Sb}_{2} \mathrm{Te}_{3}[27]$

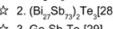
is $3 . \mathrm{Ge}_{3} \mathrm{Sb}_{2} \mathrm{Te}_{2}[29]$

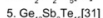

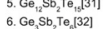
7. $\mathrm{Ge}_{3}, \mathrm{Sb}^{2} \mathrm{Te}_{1,132]}$

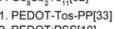

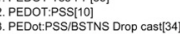
4. PEDOT:PSS IBSTNS Spincoaal34 5. PEDOT:PSS/Graphenel39:
6.HCI doped PANI36]

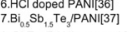

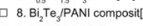
9. PEDTTPSS Film (PH 510 doped with DMSO)|39]
10. PPDOT:PS films
(PH750 doped with DMSO) 4 40] - 11. $\mathrm{PEDOT}$ w $\mathrm{PSS} / \mathrm{Bi}_{2} \mathrm{~T}_{3}$ with different volume [14]
12. PEDOT PSSTTe films [13] AST nanowire + PEDOT EG $6 \%$
GST nanowire + PEDOT EG GST nanowire + PEDOT EG $8 \%$
GST nanowire + PEDOT EG $10 \%$
GST nanowre + PEDOT EG 6\% GST nanowire + PEDOT EG $8 \%$
GST nanowire + PEDOT EG $10 \%$

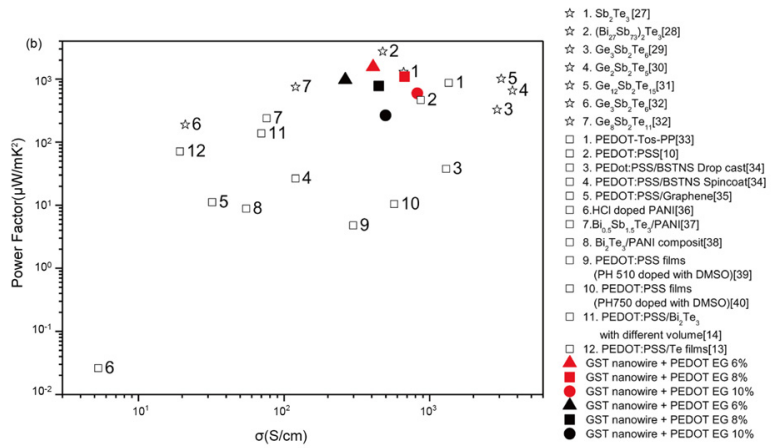

Fig. 8. Comparison of Seebeck coefficient (a), and power factor (b) of GST nanowires/PEDOT:PSS composites as a function of electrical conductivity. The EG doping concentration was varied in the range of 6 to $10 \%$. Measurement direction was also controlled in order to observe its effects as well. The literature values of GST and its composites with various organic materials were plotted to investigate the effect of GST nanowires/PEDOT: PSS composites on thermoelectric performance.

또한 전기전도도가 증가하는 모습을 보여주었다. 이는 PEDOT:PSS가 composite에서 matrix 역할을 해주어 PEDOT: PSS의 전기전도도가 composite의 전기전도도에 영향을 주고 있음을 알 수 있다. 또 가로로 측정한 composite은 세로로 측 정한 composite에 비하여 제벡계수는 그대로임에 반해 전기 전도도가 2배 이상 크게 측정 되었음을 확인할 수 있었다. Composite은 EG 6\%에서 제벡계수가 최대값인 $195.2 \mu \mathrm{V} / \mathrm{K}$ 을 얻었다. 이는 그림에 나타난 무기물을 제외한 유무기 복합 체와 비교하였을 때 상당히 높은 값이다. 또한 전기전도도는 $\mathrm{EG} 10 \%$ 에서 최대 $823.8 \mathrm{~S} / \mathrm{cm}$ 로 측정되었다.

그림 8(b)는 composite의 파워팩터와 전기전도도를 나타 내었다. EG 6\% PEDOT:PSS/ects/of GSE daEG 6\% GST nanowire/PEDOT:PSS composite을 가로로 측정하였을 때, 가장 높은 값인 $1557 \mu \mathrm{W} / \mathrm{mK}^{2}$ 이 계산되었고, $\mathrm{EG} 10 \% \mathrm{GST}$ nanowire/PEDOT:PSS composite을 세로로 측정 하였을 때, $264.4 \mu \mathrm{W} / \mathrm{mK}^{2}$ 로 최소 파워팩터가 계산되었다. 이 값은 reference로 포함시킨 다른 유, 무기 복합체보다 뛰어난 값을 
보여줌을 알 수 있으며, 제벡계수가 감소하지 않고, 전기전도 도를 향상시켰다는 점에서 열전 파라미터인 제벡계수와 전 기전도도 사이의 de-coupling효과라고 볼 수 있다.

\section{4. 결 론}

본 연구에서는 PEDOT:PSS에 Ethylene glycol을 도핑 했 을 때 일어나는 열전 특성의 변화와 GST 복합체의 측정방향 에 따른 전기적 및 열전 특성을 측정 하였다. PEDOT:PSS 필 름의 제벡계수 측정 결과 Pristine PEDOT:PSS가 최대 16.06 $\mu \mathrm{V} / \mathrm{K}$ 의 값을 가지고 있었으며, 전기전도도는 PEDOT:PSS에 $\mathrm{EG}$ 를 $10 \mathrm{vol} \%$ 로 도핑 하였을 때, 최대 $742.7 \mathrm{~S} / \mathrm{cm}$ 의 값이 나 왔다. 또한 파워팩터는 $\mathrm{EG}$ 가 $8 \%$ 도핑 되었을 때 최대 $12.37 \mu$ $\mathrm{W} / \mathrm{mK}^{2}$ 이라는 값이 계산되었다.

$\mathrm{GST}$ 복합체의 경우, 측정방향에 수직한 방향으로 측정하 였을 때보다 평행한 방향으로 측정 하였을 경우 전기전도도 가 증가함을 확인 할 수 있었다. 반면 제벡계수의 경우는 일 정한 값으로 유지 되었고 결과적으로 향상된 파워팩터(=제 벡계수 ${ }^{2}$ 전기전도도)를 얻을 수 있었다. 그 결과 복합체는 상 온에서 최대 $195.2 \mu \mathrm{V} / \mathrm{K}$ 라는 높은 제벡계수가 측정되었고, 전기전도도는 $823.84 \mathrm{~S} / \mathrm{cm}$ 가 측정 되었다. 파워팩터는 $\mathrm{EG}$ 를 $6 \%$ 도핑한 상태에서 가로로 측정 하였을 때 최대 $1550 \mu$ $\mathrm{W} / \mathrm{mK}^{2}$ 으로 나타난다. 이는 기존의 보고된 bulk $\mathrm{Ge}_{2} \mathrm{Sb}_{2} \mathrm{Te}_{5}$ 파워팩터 $370 \mu \mathrm{W} / \mathrm{mK}^{2}$ 보다 약 4 배 높은 열전 특성을 가진 다. 또 기존의 PEDOT:PSS의 파워팩터 $330 \mu \mathrm{W} / \mathrm{mK}^{2}$ 에 대해 서 5 배이고, GST 박막의 파워팩터 $320 \mu \mathrm{W} / \mathrm{mK}^{2}$ 에 대해서는 5배, PEDOT:PSS/Te films복합체의 파워팩터 $70.9 \mu \mathrm{W} / \mathrm{mK}^{2}$ 에 비해서는 22 배이다. 일반적으로 제벡계수는 전기전도도 와 반비례관계로 열전물질의 전기전도도가 증가하는 경우 제벡계수는 감소하는 것으로 알려져 있다. 하지만 PEDOT: $\mathrm{PSS} / \mathrm{GST}$ nanowire arrrays 복합체의 경우 전기전도도의 증 가와 무관하게 일정 값의 제벡계수가 유지되는 결과를 얻을 수 있었는데, 이는 아마도 복합체의 전기전도도는 GST nanowire array에 비해 상대적으로 높은 전기전도도를 가지 는 PEDOT:PSS에 의존하기 때문일 것이라고 사료된다. 이와 반대로 복합체의 제벡계수의 경우는 일반적으로 알려진 유 기물질의 제벡계수(그림 8-a)보다 벌크 GST에 가깝게 나타 난 것을 비교를 통해 알 수 있다. 즉, PEDOT:PSS의 charge path way 제어를 통한 전기전도도 향상, 높은 제벡계수를 갖 는 GST nanowire array를 첨가함으로써 향상된 열전 특성을 가지는 유/무기 복합체를 얻을 수 있었다. 이러한 결과는 구
조 및 방향을 제어를 통하여 복합열전소재의 특성을 극대화 할 수 있다는 원천 기술을 제시하고 있다.

\section{감사의 글}

본 연구는 2015 년도 지식경제부의 재원으로 한국에너지 기술평가원(KETEP)의 지원을 받아 수행한 연구 과제입니다 (No. 20153030013200). 또한 재료연구소의 지원을 받아 수 행한 연구 과제입니다.

\section{REFERENCES}

1. C. B. Vining, Nature 413, 577 (2001).

2. C. Boulanger, J. Electron. Mater. 39, 1818 (2010).

3. G. S Nolas, J. Sharp, and J. Goldsmid, Thermoelectrics: Basic Principles and New Materials Developments, Springer Science \& Business Media (2013).

4. R. Venkatasubramanian, E. Siivola, T. Colpitts, and B. O'quinn, Nature 413, 597 (2001).

5. A. M. Dehkordi, M. Zebarjadi, J. He, and T. M. Tritt, Mat. Sci. Eng. $R$ 97, 1 (2015).

6. J. Lee, Z. Li, J. P. Reifenberg, S. Lee, R. Sinclair, M. Asheghi, and K. E. Goodson, J. Appl. Phys. 109, 084902 (2011).

7. J. Lee, T. Kodama, Y. Won, M. Asheghi, and K. E. Goodson, J. Appl. Phys. 112, 014902 (2012).

8. N. Dubey and M. Leclerc, J. Polym. Sci. Pol. Phys. 49, 467 (2011).

9. O. Bubnova, Z. U. Khan, H. Wang, S. Braun, D. R. Evans, M. Fabretto, P. Hojati-Talemi, D. Dagnelund, J. Arlin, and Y. H. Geerts, Nat. Mater. 13, 190 (2014).

10. G. Kim, L. Shao, K. Zhang, and K. P. Pipe, Nat. Mater. 12, 719 (2013).

11. G. J. Snyder and E. S. Toberer, Nat. Mater. 7, 105 (2008).

12. K. C. See, J. P. Feser, C. E. Chen, A. Majumdar, J. J. Urban, and R. A. Segalman, Nano Letters 10, 4664 (2010).

13. B. Zhang, J. Sun, H. Katz, F. Fang, and R. Opila, ACS Appl. Mater. Interfaces 2, 3170 (2010).

14. N. E. Coates, S. K. Yee, B. McCulloch, K. C. See, A. Majumdar, R. A. Segalman, and J. J. Urban, Adv. Mater. 25, 1629 (2013).

15. H. Ju and J. Kim, Chem. Eng. J. 297, 66 (2016)

16. Q. Yao, Q. Wang, L. Wang, and L. Chen, Energ. Environ. Sci. 7, 3801 (2014).

17. C. Meng, C. Liu, and S. Fan, Adv. Mater. 22, 535 (2010).

18. M. S. Dresselhaus, G. Chen, M. Y. Tang, R. Yang, H. Lee, D. Wang, Z. Ren, J. Fleurial, and P. Gogna, Adv. Mater. 19, 1043 (2007).

19. Y. H. Kim, C. Sachse, M. L. Machala, C. May, L. Müller Meskamp, and K. Leo, Adv. Funct. Mater. 21, 1076 
(2011).

20. K. Chang, M. Jeng, C. Yang, Y. Chou, S. Wu, M. A. Thomas, and Y. Peng, J. Electron. Mater. 38, 1182 (2009).

21. S. Ashizawa, R. Horikawa, and H. Okuzaki, Synth. Met. 153, 5 (2005).

22. H. Alam and S. Ramakrishna, Nano Energy 2, 190 (2013).

23. M. Jonson and G. Mahan, Phys. Rev. B 21, 4223 (1980).

24. D. Narducci, E. Selezneva, G. Cerofolini, S. Frabboni, and G. Ottaviani, J. Solid State Chem. 193, 19 (2012).

25. M. He, J. Ge, Z. Lin, X. Feng, X. Wang, H. Lu, Y. Yang, and F. Qiu, Energ. Environ. Sci. 5, 8351 (2012).

26. S. K. Yee, N. E. Coates, A. Majumdar, J. J. Urban, and R. A. Segalman, Phys. Chem. Chem. Phys. 15, 4024 (2013).

27. L. M. Gonçalves, C. Couto, P. Alpuim, D. M. Rowe, and J. H. Correia, Mater. Sci. Forum 514, 156 (2006).

28. A. Boulouz, S. Chakraborty, A. Giani, F. P. Delannoy, A. Boyer, and J. Schumann, J. Appl. Phys. 89, 5009 (2001).

29. L. Shelimova, O. Karpinskii, P. Konstantinov, M. Kretova, E. Avilov, and V. Zemskov, Inorg. Mater. 37, 342 (2001).

30. F. Yan, T. Zhu, X. Zhao, and S. Dong, Appl. Phys. A 88,
425 (2007).

31. T. Rosenthal, M. N. Schneider, C. Stiewe, M. Döblinger, and O. Oeckler, Chem. Mater. 23, 4349 (2011).

32. E. Sittner, K. S. Siegert, P. Jost, C. Schlockermann, F. R. L. Lange, and M. Wuttig, Phys. Status Solidi A 210, 147 (2013).

33. T. Park, C. Park, B. Kim, H. Shin, and E. Kim, Energ. Environ. Sci. 6, 788 (2013).

34. Y. Du, K. Cai, S. Chen, P. Cizek, and T. Lin, ACS Appl. Mater. Interfaces 6, 5735 (2014).

35. G. H. Kim, D. H. Hwang, and S. I. Woo, Phys. Chem. Chem. Phys. 14, 3530 (2012).

36. J. Li, X. Tang, H. Li, Y. Yan, and Q. Zhang, Synth. Met. 160, 1153 (2010).

37. X. Zhao, S. Hu, M. Zhao, and T. Zhu, Mater. Lett. 52, 147 (2002).

38. N. Toshima, M. Imai, and S. Ichikawa, J. Electron. Mater. 40, 898 (2011).

39. K. Chang, M. Jeng, C. Yang, Y. Chou, S. Wu, M. A. Thomas, and Y. Peng, J. Electron. Mater. 38, 1182 (2009).

40. M. Scholdt, H. Do, J. Lang, A. Gall, A. Colsmann, U. Lemmer, J. D. Koenig, M. Winkler, and H. Boettner, J. Electron. Mater. 39, 1589 (2010). 